\title{
NA SENDA DA (RE)PRODUÇÃO SOCIAL: PRÁTICAS ORGANIZACIONAIS E QUALIDADE DE VIDA
}

\author{
Carlos Veloso da Veiga ${ }^{1}$ \\ Luísa Martins Fernandes ${ }^{2}$
}

\section{Resumo}

Este artigo se baseia num estudo de cariz comparativo realizado em quatro organizações de formação e reabilitação profissional de pessoas com deficiência intelectual sedeadas no Norte de Portugal (duas) e na Região Autônoma da Galiza - Espanha (duas). A partir da pesquisa desenvolvida, procurase compreender e explicar a ação dos agentes dessas organizações, atendendo às práticas com que pretendem desenvolver a autonomia dos seus formandos e futuros trabalhadores, em dois domínios próprios das dimensões de autodeterminação e vida independente que integram o conceito de Qualidade de Vida: usufruto dos tempos livres e mobilidade no espaço público. Para efeito, mobilizam-se alguns dos principais conceitos da Teoria da Estruturação de Giddens, tendo como principal objetivo compreender e explicar as consequências das práticas dos agentes organizacionais no seu contributo para a reprodução ou a transformação do sistema de regras sociais sobre a deficiência. Metodologicamente, recorre-se aos testemunhos de vários atores (pessoas com deficiência intelectual, seus amigos, colegas de trabalho, familiares, empregadores, formadores, diretores das organizações e especialistas em reabilitação profissional), recolhidos por entrevistas semiestruturadas e inquéritos por questionário. Os resultados obtidos apontam para que agentes das organizações de reabilitação do Norte de Portugal exerçam a agência, no sentido das suas práticas tenderem para a reprodução do sistema de regras sociais da deficiência, em contraponto ao que acontece em Galiza. Nesta região, as práticas dos agentes das organizações de reabilitação profissional tendem a questionar o socialmente instituído, contribuindo, sobretudo, para a transformação do sistema de regras sociais da deficiência, em aproximação aos ideais da inclusão social, determinados pelos conceitos autodeterminação e vida independente.

Palavras-chave: Qualidade de vida. Regras. Autodeterminação. Vida independente. Reprodução. Transformação.

\begin{abstract}
This article is based on a comparative study made in four professional formation and rehabilitation organizations of people with intellectual deficiency placed in the North of Portugal (two) and in Galicia - Spain (two). From the research developed, we attempt to understand and explain the action of the agents of theses organizaitions, trying to achieve the practices which aim to develope the

\footnotetext{
${ }^{1}$ Doutor em Sociologia, Universidade do Minho - Centro de Estudos e Comunicação e Sociedade [CECS], Braga, Portugal, cveiga@ics.uminho.pt

${ }^{2}$ Doutora em Sociologia, Universidade do Minho - Centro de Estudos e Comunicação e Sociedade [CECS], Braga, Portugal, luisaoliveiram@gmail.com
}

Fed. Nac. das Apaes- Fenapaes $\mid$ Brasília/DF | v.1 | no 9

P. $22-43$

| jan./jun.2018|ISSN 2237-4329| 
autonomy of its students and future workers, in two onw domains of the dimensions of self determination and independent life which integrate the concept of Quality of Life: using free-time and mobility in the public space. For this purpose, there are some concepts on the Structuration Theory of Giddens, with the main objective of understanding and explaining the consequences of the practices of organizational agents in their role to reproduce or tranform the rule system of social rules about the defieciency. Methodologocally, there are several testimonies of actors (people with intellectual deficiency, their friends, work colleagues, relatives, employees, instructors, organization directors and especialists in professional rehab), collected by semi structured interviews and survey by questionnaire. The results point for the organization agents of rehabilitation in the north of Portugal practicce the acting, in the sense of them to reproduce the social rule deficiency's system, in opposite to what happens in Galicia. In this region, the practices of the agents tend to question what has been socially instituted, contributing for the transformation of social rules of the deficiency, getting close to the ideas of social inclusion, determined by the concepts self determination and independent life.

Keywords: Quality of life. Rules. Self determination. Independent life. Reproduction. Transformation.

\section{INTRODUÇÃO}

Neste artigo, com base no modelo de Qualidade de Vida de Veiga, Fernandes, Saragoça, Silva e Domingues (2014, p. 25 - 28), são apresentadas, analisadas e comparadas algumas práticas dos agentes das organizações de reabilitação profissional das regiões Norte de Portugal e Autônoma da Galiza. Como finalidade, procura-se compreender e explicar o seu contributo para a reprodução e/ou transformação do sistema de regras sociais sobre a deficiência, práticas, que podem ser consideradas próprias das dimensões de autodeterminação e vida independente presentes no modelo de Qualidade de Vida supracitado.

Damos especial relevo às consequências das práticas dos agentes das organizações de reabilitação profissional de pessoas com Deficiência Intelectual (DI) no seu contributo para a reprodução e/ou transformação do sistema de regras sociais da deficiência, tendo como suporte as dimensões de autodeterminação e vida independente presentes no modelo de Qualidade de Vida utilizado na pesquisa (VEIGA et al, 2014; FERNANDES, 2017).

Tais consequências se explicam à luz da Teoria da Estruturação de Giddens (2003), com a qual se analisa a ação dos agentes das organizações de reabilitação profissional, com especial atenção nas práticas que desenvolvem para proporcionarem aos seus formandos e, sobretudo, aos futuros trabalhadores com Deficiência Intelectual (DI), competências em dois dos vários domínios das dimensões do conceito de Qualidade de Vida. Em suma, a nossa principal finalidade é evidenciar

|Fed. Nac. das Apaes- Fenapaes $\mid$ Brasília/DF | v.1 | no 9

P. $22-43$

| jan./jun.2018 |ISSN 2237-4329| 


\section{Apøe Ciênciø Artigo}

apaeciencia.org.br/revista

numa perspetiva internacional comparada, segundo Keith e Schalock (2000), relacionar as práticas dos agentes das organizações à produção ou reprodução de regras que compõem o sistema de regras sociais sobre a deficiência, sobretudo enquanto consequências não intencionais da ação, nos termos do conceito de "dualidade da estrutura", conceito fundamental da Teoria da Estruturação.

\section{METODOLOGIA E ENQUADRAMENTO TEÓRICO}

\section{Metodologia e técnicas de pesquisa}

Metodologicamente, realizou-se uma combinação de procedimentos, numa interação entre métodos quantitativos e qualitativos (FIELDING; SCHERIER, 2001; FLICK, 2005; CRESWELL, 2003; STRAUSS; CORBIN, 2008) e se efetuou uma triangulação intermétodos (DUARTE, 2009), pelo cruzamento de informação proveniente de várias fontes, para ser possível alcançar os propósitos da pesquisa (CHARMAZ, 2006). Por um procedimento aleatório e por multietapas, obteve-se uma amostra de 24 trabalhadores com deficiência intelectual (DI), constituída por 14 homens e 10 mulheres. A composição da amostra desses trabalhadores com DI, iniciou-se com a adesão voluntária de quatro organizações de reabilitação profissionais de pessoas com deficiência intelectual, que comprometeram com o apoio logístico e a participação na pesquisa.

Foram analisadas duas das organizações sediadas na Região Norte de Portugal e duas na Região Autônoma da Galiza (Espanha). Aos trabalhadores que integraram a amostra foram aplicados questionários de administração indireta, com várias perguntas abertas. Solicitou-se que eles indicassem, para efeitos de realização posterior de entrevistas semiestruturadas, um familiar com maior convivência, um ou mais amigos e colegas de trabalho que pudessem constituir-se como informantes-chave. Igualmente, os seus patrões ou responsáveis das organizações empregadoras (maioritariamente proprietários de pequenas e médias empresas) foram incluídos na mesma condição. No total, colaboraram na pesquisa 150 pessoas, englobando, também, seis diretores técnicos das organizações de reabilitação profissional e dois especialistas em questões relacionadas com o emprego de pessoas com deficiência intelectual, aos quais se realizaram entrevistas aprofundadas.

Aos formadores dos trabalhadores com DI foram também aplicados questionário de administração direta. Todas as entrevistas realizadas foram gravadas, com o consentimento informado dos entrevistados e, posteriormente, submetidas às regras de análise de conteúdo, usandose tabelas com categorias predefinidas, orientadas pelas dimensões do modelo de qualidade de vida 
adotado (BARDIN, 2011; AMADO, 2000; GUERRA, 2012). Foram ainda construídas duas bases de dados no programa Statistical Package for the Social Sciences (SPSS) para o tratamento das respostas aos questionários aplicados aos trabalhadores com deficiência, recorrendo-se, em especial, às tabelas por frequência e de dupla entrada para cruzar dados provenientes de duas variáveis (especialmente a variável região de origem).

\section{Caraterização dos trabalhadores com DI da amostra}

Os 24 trabalhadores com DI, que compõem a amostra, têm média de idades de 29, 71 anos, possuem habilitações literárias diversas e globalmente baixas, em geral, no que tange ao nível do Ensino Básico, trabalham maioritariamente em organizações do setor privado, somando 22 casos. Os restantes trabalham em organizações do setor público, em duas câmaras municipais, uma na Região Norte de Portugal e outra na Região Autônoma da Galiza.

As empresas privadas empregadoras se distribuem por diversas áreas de atividade, tais como: cabeleireiro, centro de lavagem de automóvel, supermercado, pizzaria, empresas farmacêuticas, serviços domésticos (vulgo "mulher a dia"), incluindo as próprias organizações de reabilitação profissional. As categorias profissionais identificadas são pouco ou nada qualificadas, exigindo pouca formação acadêmica, i.e., operários não especializados, ajudantes (de pizzaria, cabeleireiro, cavalariças, lavagem automotiva), assistentes operacionais, trabalhadores auxiliares ou indiferenciados, empregadas(os) de limpeza e cozinha, colaboradores de armazém, dentre outras das categorias profissionais mais baixas nas respetivas profissões ${ }^{3}$.

\section{Teoria e conceitos mobilizados}

A Teoria da Estruturação se constitui como uma boa ferramenta teórica dada a sua especial capacidade para ajudar na compreensão e explicação da ação humana ao ligar a ação dos agentes organizacionais à (re)estruturação dos sistemas sociais. Fazendo uso do seu elevado valor heurístico, procura-se explicar, à luz da Teoria da Estruturação de Giddens (1979, 2003), quais são e como se manifestam as consequências da ação dos agentes das organizações de reabilitação profissional, que

\footnotetext{
${ }^{3}$ Existe um caso na região da Galiza no qual o trabalhador com deficiência é auxiliar administrativo numa entidade pública e aufere um salário superior a 1000 euros (tem contrato de dois anos, pois é o que a legislação permite para a Administração pública. Uma vez terminado o contrato, ele não tem possibilidades de progresso, porque as reservas para pessoas com deficiência mental são poucas e as que existem são dirigidas às pessoas com deficiência física).
}

| Fed. Nac. das Apaes- Fenapaes $\mid$ Brasília/DF | v.1 | no 9 | P. 22 - 43 | jan./jun.2018 | ISSN 2237-4329| 


\section{Apøe Ciênciø Artigo}

apaeciencia.org.br/revista

resultam das práticas com que pretendem desenvolver competências que se enquadram nas dimensões de autodeterminação e vida independente, presentes no modelo de Qualidade de Vida adotado. A finalidade é relacionar as práticas dos agentes das organizações de reabilitação à reprodução ou à transformação das normas que integram o sistema de regras sociais sobre a deficiência, quando agem no sentido de preencher os futuros trabalhadores com DI de competências para a realização autodeterminada de atividades de tempos livres, recreação e lazer, bem como de autonomia para a mobilidade no espaço público.

A Teoria da Estruturação de Giddens, que se pauta na ação humana em termos de significação, legitimação e dominação, é constituída por um complexo corpus de conceitos de elevado valor heurístico, os quais podem ser mobilizados para a compreensão e explicação das práticas sociais. Referimo-nos, especialmente, aos conceitos de ação, agente e agência, regras e recursos, consciência discursiva e consciência prática, dualidade da estrutura e consequências não intencionais da ação. $\mathrm{O}$ agente, de acordo com Giddens (2003, p. 331), refere-se à condição do ser humano como ator informado, competente e cognoscitivo. Na verdade, os atores sociais sabem muito sobre as condições e consequências do que fazem no seu dia a dia e têm capacidade para descreverem, via discursiva, o que fazem e porque o fazem, atribuindo-lhe significado.

A consciência prática, que induz o indivíduo a expressar o que percebe, do modo como o vê, o que fazem de fato, é distinta da capacidade dos indivíduos de exprimirem com palavras o que fazem - consciência discursiva. As consequências não intencionais da ação se caraterizam por serem os resultados não previstos das práticas realizadas pelos agentes sociais. A agência, que é um fluxo contínuo e dinâmico, resulta da intenção e dos objetivos dos atores em atingirem determinados resultados. Já a ação é um processo contínuo, em que a monitorização reflexiva do comportamento de cada indivíduo é fundamental para os seus comportamentos ao longo da vida, enquanto a dualidade da estrutura em interação representa a reprodução e/ou a transformação da vida social (GIDDENS, 2003).

O recurso à Teoria da Estruturação e os seus conceitos implicam em se levar em consideração a relação entre a deficiência e a sociedade que se encontra estruturada, com base na aplicação de regras sociais que se foram configurando, num sistema específico, referido anteriormente como sistema de normas sociais sobre a deficiência. Tal sistema de preceitos, composto essencialmente por regras de sentido negativo para os interesses das pessoas com deficiência, foi-se formando e consolidando nos mais diversos espaços sociais e evoluindo ao longo do tempo histórico.

| Fed. Nac. das Apaes- Fenapaes $\mid$ Brasília/DF | v.1 | no 9 | P. 22 - 43 | jan./jun.2018 |ISSN 2237-4329| 


\section{Apøe Ciênci@ Artigo}

apaeciencia.org.br/revista

Destacamos, de acordo com Burns e Flam (2000), as regras prescritivas (que especificam como os atores da relação se devem comportar e quais os meios legítimos, ou pelo menos aceitáveis, para lutar por aquilo que é definido como positivo ou válido nas esferas da ação das relações sociais) e as regras classificativas (que distinguem diferentes tipos de ação social, atores, ações e interações, resultados, acontecimentos e tudo o que é relevante numa relação entre atores individuais ou coletivos).

De acordo com Burns e Flam (2000, p. 11 - 12), os sistemas de regras regulam as interações entre agentes, definem direitos e obrigações, regras de comando e obediência, que regulam categorias específicas de atores ou de papéis na relação com os outros. Apresentamos alguns exemplos de regras classificativas e prescritivas do sistema de regras sociais da deficiência, que tendem a patrocinar a exclusão, a marginalização, a dependência, a estigmatização e a segregação das pessoas com deficiência (LABREGÈRE, 1981; VEIGA, 2006), algumas das quais serão particularmente relevantes na compreensão do aqui exposto: a) Regras Classificativas: Membros da sociedade não produtivos e não competitivos; Pessoas com menos capacidades do que as outras; Não competentes para se movimentarem no espaço público; Não conseguem trabalhar ou competir com ou como as pessoas “normais"; Não têm direito à opinião, nem a se fazerem ouvir; Incompetentes para cuidarem de se próprias; Incapazes de lidarem de forma autônoma com o seu próprio dinheiro; Dependentes de outras pessoas; Têm comportamentos infantilizados; Não têm capacidade para consumirem uma parte dos bens e serviços socialmente disponíveis; Não conseguem imitar e seguir os estilos de vida das pessoas "normais"; 2) Regras prescritivas: Devem ser alvo de segregação e marginalização; Devem ser alvo de controle social permanente (vigilância e acompanhamento de profissionais especializados); Devem ser supervisionadas e protegidas pelos familiares; Devem ser desculpadas quando têm comportamentos extravagantes ou excêntricos; Devem ser repreendidas pelas outras pessoas mesmo quando são pessoas adultas; Devem ser controladas no exercício das atividades da sua vida quotidiana; Devem ser alvo de caridade e solidariedade; Não vale a pena tentar potenciar as suas qualidades pessoais; Devem ser prioritariamente descartadas pelas organizações empregadoras.

De acordo com Veiga, Fernandes e Saragoça (2016, p. 31), a qualidade de vida dos DI, tal como acontece com as outras pessoas, passa pela sua participação ativa em ambientes sociais comuns, englobando, obrigatoriamente, estar na posse de competências que lhes permitam ser autodeterminadas e terem uma vida independente. A "autodeterminação é a autonomia para decidir. Significa a capacidade de tomar as próprias decisões, agir de forma decisiva e atuar com determinação (ser firme nas decisões). A autodeterminação pressupõe assimilação do poder de controlo e de decisão

| Fed. Nac. das Apaes- Fenapaes $\mid$ Brasília/DF | v.1 | no 9 | P. 22 - 43 | jan./jun.2018 | ISSN 2237-4329 | 


\section{Apøe Ciênciø Artigo}

apaeciencia.org.br/revista

pela própria pessoa. É um processo onde as pessoas vão adquirindo habilidades e desenvolvendo as atitudes necessárias que lhes permitem, em boa medida, ser responsáveis pelo que sucede nas suas vidas" (VEIGA; SILVA, 2014, p. 190).

É pela posse e pelo uso dessas competências que, tal como a maioria das pessoas, as que possuem DI podem explorar e praticar os vários papéis sociais, desfrutando das oportunidades de participarem, de forma inclusiva, na edificação da sociedade e obterem uma melhoria da qualidade de vida, particularmente quando acedem ao mercado de trabalho. Importa, por isso, aclarar o que se deve entender como Qualidade de Vida, conceito de difícil definição, que não passa imune à crítica (MOON; BUDTS; GEEST, 2006) devido à subjetividade e à complexidade que lhe está inerente, apresentando, de uma forma sucinta, algumas definições presentes na literatura sobre o tema. Assim, a Qualidade de Vida está, antes de mais nada, diretamente relacionada com a perceção que cada um tem de si e dos outros (ABRAMS, 1973; ANDREWS, 1974; BADIA; PATRICK, 1995). Isso pode, de igual modo, ser entendido, como a satisfação com a vida (CUMMINS, 1996) ou, também, como proposto por Cummins (1997, p. 119), como “objetiva e subjetiva, envolvendo o bem-estar material, saúde, produtividade, intimidade, segurança, comunidade e o bem-estar emocional", no que é acompanhado por outros autores como Lawton (1991), Carr e Hingginson (2001), Schalock e Verdugo (2003), Gómez-Vela e Sabeh (2006), Moons, Budts e De Geest (2006). Pertencerá a Schalock (1996), citado por Veiga et al. (2014, p. 22), a definição de qualidade de vida aplicada à deficiência intelectual mais aceita pela comunidade científica.

Segundo essa definição, as condições de vida desejadas por uma pessoa estão em sintonia com as oito necessidades fundamentais: bem-estar emocional, relações interpessoais, bem-estar material, desenvolvimento pessoal, bem-estar físico, autodeterminação, inclusão social e direitos. Para além da variedade de definições são inúmeros os seus modelos que reúnem consenso sobre a sua multidimensionalidade, tendo por base indicadores objetivos e subjetivos.

Dada a relevância da explanação das dimensões de autodeterminação e vida independente, para o tema aqui tratado, importa apresentar e discutir qual o entendimento lhes é dado na literatura sobre Qualidade de Vida. Desde logo, importa reter que a primeira referência na literatura sobre autodeterminação adaptada às pessoas com deficiência surge com Nirje (1972), citado por Wehmeyer (2001, p. 119), num texto intitulado "O direito à autodeterminação". De acordo com o autor, a autodeterminação permite às pessoas controlarem as suas vidas e destinos, incluindo eleições nas 
atividades pessoais, controle na educação, independência, participação em decisões, informação sobre a tomada de decisões e a resolução de problemas.

Portanto, apesar das suas limitações físicas, sensoriais ou cognitivas e das barreiras sociais e atitudinais que enfrentem as pessoas com deficiência, elas podem ser ou se tornarem pessoas autodeterminadas (WEHMEYER; SCHALOCK, 2001; WEHMEYER; SCHWARTZ, 1998). De acordo com Wehmeyer (2006, p. 5), é esse "modo de entender a autodeterminação que determina o tipo de oportunidades que se oferecem às pessoas com deficiência para que se convertam em indivíduos mais autodeterminados”. Nirje (1972) reconhece que a autodeterminação é fundamental para que se alcance o respeito, a dignidade e para que as pessoas se sintam dignas e valorizadas. $\mathrm{O}$ autor acrescenta que se deve colocar acessível às pessoas com deficiência as orientações e condições de vida quotidiana que sejam tão próximas quanto possível às normas e orientações do corpo principal da sociedade e que se deve criar condições para que experimentem o respeito normal a que qualquer ser humano tem direito.

Do ponto de vista de Wehmeyer (2006, p. 9), "numa conduta autodeterminada deve atuar-se como agente causal primário da própria vida, realizar eleições e adotar decisões sobre a própria qualidade de vida livre de influências ou interferências externas inapropriadas". Um dos componentes da autodeterminação é o usufruto dos tempos livres em atividades de lazer e recreação, que incrementam a autoestima e aumentam o bem-estar físico e psicológico. Trata-se de atividades que envolvem escolhas, proporcionando oportunidades para que se adquiram habilidades e competências na interação social e, assim, prosperarmos como membros das comunidades a que pertencemos.

Centremos agora as nossas atenções no conceito de Vida Independente, cuja compreensão obriga, antes de mais nada, a atentar-se ao conceito de independência, que nos remete a situação de uma pessoa não depender de outra para participar de forma socialmente ativa e controlar o seu próprio destino. Segundo García Alonso (2003), as pessoas se tornam independentes quando saem da casa dos pais e iniciam uma nova etapa das suas vidas, assumindo riscos pessoais, tais como: encontrar trabalho que garanta a independência, ter uma casa, decidir a sua decoração, a quem convidar, decidir os horários das refeições, dentre outros aspectos. Ser independente também acarreta assumir responsabilidades menos atrativas, como, por exemplo, levantar mais cedo, manter um emprego assalariado para pagar a renda do apartamento, os impostos, as faturas mensais, organizar e dar atenção às relações pessoais.

| Fed. Nac. das Apaes- Fenapaes $\mid$ Brasília/DF | v.1 | no 9

P. 22 - 43 |jan./jun.2018| ISSN 2237-4329| 


\section{Apøe Ciênci@ Artigo}

A independência, num plano mais filosófico e político, define a atitude perante a vida, supõe a liberdade de eleição do destino, tendo controle sobre os próprios atos e pensamentos, podendo-se eleger entre diferentes opções de vida. É um princípio orientador que permite alcançar os objetivos universais de igualdade de oportunidades, plena participação na sociedade e liberdade individual.

Na opinião de Cordeiro (2009), para compreendermos o conceito de Vida Independente, é também preciso ter noção dos conceitos de independência, autonomia, empoderamento, autodeterminação, participação e igualdade de oportunidades. A filosofia de vida independente, segundo Iánez (2009), parte da ideia de que todas as pessoas têm direito à independência pelo máximo controle sobre as suas vidas, baseada na capacidade e na oportunidade para tomar decisões e levar a cabo as atividades de cada dia.

Os princípios que devem embasear qualquer iniciativa de Vida Independente são: dignidade; autodeterminação para tomar decisões; não discriminação das pessoas com deficiência, gozando de estatuto e cidadania plena; vida comunitária pela participação e inclusão plena e efetiva na sociedade; direito a viver de forma independente; diversidade pela aceitação das pessoas com deficiência como parte da diversidade e da condição humana; igualdade de oportunidades pela ausência de discriminação direta ou indireta, cumprimento dos requisitos de acessibilidade e de ajustes razoáveis, bem como o cumprimento das medidas de ação positiva legalmente estabelecidas; acessibilidade ao seu ambiente, a um apartamento e à tecnologia necessária; igualdade de género; respeito pelas competências das crianças, facilitando processo individual de desenvolvimento individual e a sua identidade específica (CENTENO; LOBATO; ROMAÑACH, 2008, p. 15).

De acordo com o Manifesto de Tenerife (2003), a vida independente é um direito humano fundamental para todas as pessoas com deficiência, independentemente da natureza e alcance da sua deficiência. Na vida quotidiana das pessoas, ter autonomia de mobilidade no espaço público é fundamental para aceder a lugares diversos, seja para desempenhar funções sociais relevantes, seja para realizar tarefas mais rotineiras, próprias das diversas atividades do dia a dia. A presença no mercado de trabalho torna ainda mais necessária tal autonomia, sobretudo no uso dos transportes públicos, sem acompanhamento e orientação de outras pessoas. 


\section{APRESENTAÇÃO E DISCUSSÃO DE RESULTADOS}

\section{Autodeterminação e usufruto dos tempos livres}

Dando como exemplo o usufruto dos tempos livres em atividades de recreação e lazer, a pesquisa mostra que os agentes das organizações de reabilitação da região Norte de Portugal realizam algumas práticas formativas, que visam tornar os futuros trabalhadores com DI competentes para decidirem o que querem fazer nos seus tempos livres, elegendo as atividades que desejam realizar. Para alcançarem os resultados, os agentes das organizações usam alguns dos recursos distributivos de que dispõem e controlam, nomeadamente, recursos humanos (formadores e outros profissionais) instalações, viaturas e equipamentos, para apoiarem e estimularem os futuros trabalhadores a participarem em diversas atividades de forma autodeterminada, tal como acontece com a maioria dos restantes cidadãos.

No entanto, apesar dos agentes das organizações de reabilitação afirmarem discursivamente, via consciência discursiva, que exercem a agência para que os futuros trabalhadores com DI sejam autodeterminados no usufruto dos seus tempos livres, a maioria das práticas relacionadas com atividades de lazer e recreação são realizadas no interior das instalações das próprias organizações, no seio das quais os futuros trabalhadores, praticam jogos virtuais, esportes diversos (voleibol, atletismo, futebol, natação) ou integram ranchos folclóricos.

Há outras atividades que são praticadas no exterior, como as idas ao cinema, à praia ou ao restaurante. Todavia, são esporádicas e realizadas em grupo, sob a vigilância e a supervisão dos agentes organizacionais, não treinando o necessário para que fiquem autônomos nas escolhas e decisões dos seus tempos livres, modificando hábitos pessoais e familiares enraizados que impedem ou dificultam a adesão regular à prática de atividades de tempos ociosos.

Frequenta as oficinas de formação profissional, tem apoio de psicopedagogia, usufrui das atividades recreativas e lúdicas da instituição, informática, rancho folclórico, natação, educação física. (formador, Norte de Portugal)

Na nossa atividade enquanto estamos em formação com eles, naturalmente também muito do que fazemos é no sentido de assegurar as condições básicas, até porque não temos condições para mais [...] $\mathrm{O}$ individuo não tem propriamente hábitos de fazer outra vida para além disto, nem que seja de vez enquanto, mas não tem hábitos. Ou seja, aquilo que se fez do ponto de vista institucional não foi suficiente para criar hábitos [...] de ver uma peça de teatro ou um filme ou ao cinema também não, não gerou hábito, porque foram tão poucas vezes. Nós no fundo o que acabamos por fazer é mostrar-lhes os espaços, espaços de diversão, espaços de consumo e aferição de algum prazer de alguma cultura, espaços de cultura. Mas só lhes

Fed. Nac. das Apaes- Fenapaes $\mid$ Brasília/DF | v.1 | no 9 | P. 22 - 43 |jan./jun.2018 |ISSN 2237-4329| 
mostramos, não os treinamos para isso e, portanto, como não treinamos as pessoas depois e ainda por cima como fazem parte de agregados familiares muito pobres também a este nível, culturalmente. (especialista, Norte de Portugal)

Os resultados da pesquisa parecem provar que, embora os agentes das organizações da região Norte de Portugal afirmem exercer a agência com a intenção de transformarem o sistema de regras sociais da deficiência, pelas práticas que apoiem e estimulem a conduta autodeterminada dos futuros trabalhadores no usufruto dos tempos livres, na verdade não acautelam nem estimulam verdadeiramente a continuidade autônoma dessas práticas para além dos muros das organizações de reabilitação e/ou fora do controle social efetuado por eles próprios ou pelos familiares.

Essa forma de agir, que decorre da sua consciência prática, acarreta consequências não intencionais da ação, dentre as quais se destaca o contributo para a reprodução de duas importantes regras sociais classificativas segundo as quais as pessoas com deficiência são "incapazes de participarem socialmente, i.e., não têm poder para participar em todos os domínios do sistema social" e "não têm capacidade para consumirem parte dos bens e dos serviços disponibilizados pela sociedade".

A essas regras se junta a ação prática dos familiares que, seguindo a norma prescritiva segundo a qual as pessoas com deficiência "devem ser controladas no exercício das atividades da sua vida quotidiana" (uso de dinheiro, manejo de produtos mais delicados ou perigosos, relações amorosas, dentre outros aspectos), supervisionam a vida quotidiana e controlam a gestão dos recursos financeiros dos trabalhadores da amostra, coartando a sua liberdade de livre eleição. Esses são, em regra, familiares cujos hábitos e rotinas de não participação social se aliam à fragilidade de redes de relações de amizade pequenas, fracas e pouco estruturadas.

Nesse contexto, ainda que 11 dos 12 dos trabalhadores com DI da amostra se considerem competentes para decidirem quais as atividades desejam praticar, os resultados da pesquisa mostram que raramente exercem condutas autodeterminadas nos domínios do usufruto dos tempos livres, sendo de baixo custo as raras atividades de lazer e recreação praticadas, realizadas nas proximidades ou dentro das suas próprias casas ou, ainda, em passeios de domingo, em geral, acompanhando a família, em visitas a outros familiares.

\footnotetext{
Não tem por hábito participar em atividades sem ser as de família. (amigo, Norte de Portugal)

E depois, ao Domingo, quando a gente sai (ainda no Domingo fomos para Espanha), vai sempre com a gente. Se há um Domingo que a gente fica em casa, de manhã ele fica por lá,
} 
à tarde depois do almoço vai dar uma volta à freguesia de lambreta, chega de lambreta e é televisão até à noite. (familiar, Norte de Portugal)

Também na região Autônoma da Galiza, os agentes das organizações de reabilitação profissional evidenciam discursivamente, via consciência discursiva, que realizam práticas formativas para dotarem os futuros trabalhadores com DI de competências para gerirem os seus tempos livres de forma autodeterminada. Tal como na região Norte de Portugal, os agentes organizacionais usam recursos distributivos próprios e que controlam, tais como instalações, viaturas, equipamentos e recursos humanos (preparadores laborais, formadores e outros profissionais).

Todavia, ao invés das práticas de treinamento para o comportamento autodeterminado serem, tendencialmente, realizadas no espaço organizacional ou esporadicamente fora dele, tais práticas são enquadradas num programa específico denominado "Me Muevo", que mostra que os agentes organizacionais não seguem as regras segundo as quais as pessoas com DI são "incapazes de participarem socialmente, i.e., não têm poder para participar em todos os domínios do sistema social" e "não têm capacidade para consumirem parte dos bens e dos serviços disponibilizados pela sociedade". Pelo contrário, procuram seguir as correspondentes contrarregras. Com base nesse programa, os intervenientes formam grupos para realizarem atividades de recreação e usufruto dos tempos livres nas instalações de várias organizações existentes nas comunidades locais (associações culturais, clubes recreativos e desportivos), que passam a frequentar com regularidade. Nesse sentido, os agentes das organizações da Região Autônoma da Galiza, ao invés de centrarem as práticas para uma conduta autodeterminada no uso dos seus próprios recursos, preferem utilizar recursos disponíveis nas comunidades locais onde estão sedeados.

Com efeito, é usado também o seu prestígio social, um relevante recurso de autoridade, para descentralizarem o treinamento das competências dos futuros trabalhadores com DI, incluindo-os nas atividades coletivas nas quais participam as pessoas sem deficiência e nos espaços e equipamentos que as comunidades locais disponibilizam a todos os cidadãos. Para tal, apela-se à responsabilidade social das organizações de recreação, esporte e lazer, para que aceitem e promovam a inclusão das pessoas com deficiência nas suas atividades correntes.

Resumidamente, em termos práticos, o treinamento se inicia com a formação de vários grupos de saídas para atividades distintas, acompanhados por técnicos e voluntários. Numa fase posterior, a 
supervisão vai sendo retirada lentamente até se formarem grupo de autogestores ${ }^{4}$, capazes de gerirem as atividades de recreação e o usufruto dos tempos livres de forma autodeterminada. Em complemento, a mobilidade entre os locais das organizações-atividades de lazer-habitação e por todo o espaço público é amplamente treinada e testada.

\begin{abstract}
No programa "Me Muevo", nas aulas teóricas que têm na semana, então nas aulas de "Me Muevo", o dia a que corresponde a cada pessoa e seu grupo decidem o que querem fazer durante esse mês, esse grupo tem três saídas e nas três saídas o que querem fazer? - uma ir ao cinema, outra fazer desporto e tal. A única coisa que a professora faz a mediação é ver se elegem o mesmo. Porque o que queremos fazer é ensinar, educar em tudo. Há que ir ao museu, eu educo para que tu saibas sair. Depois quando sejas maior fazes. Estão em "Me Muevo" a partir dos 8 anos. É ali que se faz, faz-se a programação e depois dá-se aos pais para que saibam o que os seus filhos decidiram e se organizem (Diretor, Galiza)
\end{abstract}

Por conseguinte, nas organizações da região Autônoma da Galiza, os agentes organizacionais parecem agir de acordo com o que afirmam discursivamente, realizando o que intencionam fazer e obtendo os resultados previstos. Por isso, serão mais eficazes e eficientes na sua contribuição para a transformação do sistema de regras sociais sobre a deficiência, do que os agentes das organizações da região Norte de Portugal. Ou seja, com essa práxis, os agentes das organizações da região Autônoma da Galiza contrariam o disposto nas regras sociais classificativas, segundo as quais as pessoas com deficiência "são incapazes de participarem socialmente, i.e., não têm poder para participar em todos os domínios do sistema social" e "não têm capacidade para consumirem parte dos bens e dos serviços disponibilizados pela sociedade".

$\mathrm{Na}$ verdade, o treinamento com recurso ao programa "Me Muevo" também tem permitido atenuar os efeitos da supervisão quotidiana e do controle dos recursos financeiros, das responsabilidades e das vontades dos trabalhadores com DI pelos seus familiares. Ou seja, as práticas dos agentes organizacionais, usando os recursos de autoridade relativos às funções que as famílias devem desempenhar nos processos de inclusão, não aceitam passivamente que elas sigam a regra de que as pessoas com DI "devem ser controladas no exercício das atividades da sua vida quotidiana”, investindo a sua autoridade para que as famílias aceitem mudar os seus comportamentos e reconheçam e assumam a correspondente contrarregra - a de que os seus familiares com DI têm direito a serem autodeterminados na escolha e na realização das atividades de recreação e usufruto dos seus tempos livres.

\footnotetext{
${ }^{4}$ Esses grupos são compostos por pessoas com deficiência que aprenderam nas empresas a organizarem e desfrutarem dos seus tempos livres. Têm competência e autonomia para decidirem e realizarem a atividade que desejam para o seu tempo livre.
}

|Fed. Nac. das Apaes- Fenapaes $\mid$ Brasília/DF | v.1 | no 9 | P. 22 - 43 | jan./jun.2018 |ISSN 2237-4329| 
Os resultados da pesquisa parecem demonstrar que as famílias galegas estão mudando os seus esquemas de representação mental, quanto às competências dos trabalhadores com DI da amostra, deixando a conduta autodeterminada daquelas pessoas de ser um problema e uma preocupação para os seus familiares. De acordo com os resultados, os trabalhadores da amostra decidem efetivamente quais as atividades de tempos livres que desejam fazer, sendo que 11 desses 12 trabalhadores as escolhem sem séria interferência dos seus familiares.

\begin{abstract}
Mas há alguns anos as gentes olhavam-nos com a boca aberta, diziam: que estão falando, como vai trabalhar numa empresa comum? Ficou uma dinâmica muito mais de exigência da normalização, as famílias já estão assimilando, muitas famílias chegavam com essa demanda. Mas nós também criamos essa necessidade neles. Se o teu filho tem o direito de se divertir e a ter um par, eram coisas que não lhes passavam pela cabeça. Ou a sair ao ócio, ou a sair para o cinema, ou a sair de noite. (diretor, Galiza)

Vai ao ginásio sozinho. Vai fazer manutenção e faz bicicleta e às vezes joga uma partida de futebol salão com as pessoas que estiverem lá. Eles juntam e dividem-se e jogam. Nesse aspeto é autónomo. E também não gosta que eu esteja ali e que vá com ele. Quer ir sozinho e independente. (familiar, Galiza)
\end{abstract}

\title{
Vida independente e mobilidade no espaço público
}

No domínio da Vida Independente, abordamos as práticas para a mobilidade no espaço público. Nesse domínio, os agentes das organizações de reabilitação sedeadas na Região Norte de Portugal realizam algumas práticas, visando a autonomia dos futuros trabalhadores com DI em termos de mobilidade no espaço público. Nessas práticas, os agentes organizacionais recorrem aos recursos de tipo distributivo que controlam, como recursos humanos (formadores e outros profissionais), viaturas, instalações e equipamentos, para efetuarem o necessário treinamento.

Porém, ainda que o deslocamento autônoma no espaço público discursivamente, via consciência discursiva, seja considerada como indispensável à realização de uma vida independente, os agentes organizacionais realizam, via consciência prática, ações que podem ser entendidas como contrárias à sua aquisição. Por exemplo, o treinamento para a mobilidade no espaço público consiste, em regra, na organização e no desenvolvimento de atividades com recurso à formação de grupos de intervenientes, para as deslocações entre locais usando transportes públicos. Nesse sentido, podemos afirmar que são relativamente eficientes, dado que os resultados obtidos revelam que, dos 12 trabalhadores com DI da amostra, 8 utilizam os transportes públicos de modo autónomo.

Não, vou de autocarro (A tua família apoia-te na deslocação para ires e voltares do trabalho?). (trabalhador, Norte de Portugal)

Não. (uso de transporte público na deslocação casa-emprego-casa) (trabalhador, Norte de Portugal) 
Não é, todavia, prática corrente, o treinamento para que os futuros trabalhadores com DI efetuem deslocações individuais, autônomas e variadas no espaço público, preferindo os agentes organizacionais usarem as viaturas pertencentes às próprias organizações para, de modo rotineiro, os familiarizarem com os trajetos habitação-organização-habitação, i.e., buscam os futuros trabalhadores com DI nas suas casas no início da manhã e os levam de volta às mesmas casas no final da tarde. Esse processo tende a ser repetido aquando do estágio profissional ou mesmo após a entrada efetiva daquelas pessoas no mercado de trabalho. Com os treinos dos trajetos que fazem entre as habitações e as organizações que exercem (ou vão exercer) a sua atividade profissional, contam, por vezes, com o apoio de familiares, colegas de trabalho ou amigos, que habitam nas proximidades dos locais onde moram.

A forma como os agentes das organizações da Região Norte de Portugal entendem e desenvolvem competências de mobilidade no espaço público parece mostrar que, via consciência prática, estão seguindo três importantes normas do sistema de regras sociais sobre a deficiência, evidenciando-se uma espécie de subversão do que é referido ao nível discursivo.

Referimo-nos às regras classificativas, que consideram as pessoas com deficiência como as que "não são competentes para a mobilidade autónoma no espaço público" e que "devem ser supervisionadas e protegidas". Para esse efeito, agentes organizacionais não põem verdadeiramente em prática ações, ou raramente o fazem, para desenvolverem a mobilidade individual no espaço público, quando o realizam é em parceria com os familiares mais próximos e no trajeto casaorganização-casa.

As intenções por detrás dessas práticas podem ser rotuladas como "boas intenções", mas produzem consequências não intencionais que reproduzem aquelas regras, se analisadas à luz do conceito de Vida Independente, enquanto dimensão do conceito de Qualidade de Vida, pelo que contribuem, de modo não previsto, nem intencional, para a reprodução do sistema de regras sociais sobre a deficiência.

Do que eu sei, a nível de transportes ao vir para a instituição, acho que não tinha grandes problemas, visto que era uma carrinha da C. que a trazia a ela, juntamente com outros miúdos. (formador, Norte de Portugal)

É a sua mãe que a leva e vai buscar de casa para o trabalho e vice-versa. (formador, Norte de Portugal)

Na prática, a ação dos agentes das organizações da Região Norte de Portugal não parece produzir competências suficientes para que os futuros trabalhadores se mobilizem de forma autônoma 
no espaço público quando ingressam no mercado de trabalho, na medida em que, na sua generalidade, continuam a depender do apoio dos outros para o fazerem. O seu espaço de vida quotidiana permanece praticamente inalterado, algo que tem muitas implicações na sua qualidade de vida e no aproveitamento de oportunidades de melhoria da mesma, como parece demonstrar o fato de apenas quatro dos trabalhadores da amostra manifestarem alguma autonomia em termos de mobilidade para lugares que não pertencem às rotinas da vida quotidiana.

No caso da Região Autônoma da Galiza, os agentes das organizações de reabilitação profissional também afirmam, via consciência discursiva, que realizam práticas de treinamento que visam dotar os futuros trabalhadores com DI de autonomia para a mobilidade no espaço público, usando transportes públicos. Para o efeito usam alguns dos recursos distributivos que controlam, em especial, os recursos humanos (preparadores laborais, formadores e outros profissionais), organizando e dinamizando programas específicos, cuja finalidade é proporcionar uma melhoria da qualidade de vida dos intervenientes, preparando-os para que possam ter uma vida independente, beneficiando-se da autonomia de deslocamento no espaço público. Também fazem uso de recursos de autoridade, nomeadamente do poder de persuasão sobre as famílias dos intervenientes, para que essas adiram às práticas de promoção da autonomia em mobilidade no espaço público: “As famílias já estão assimilando [...] Mas nós também criamos essa necessidade neles [...]”. (diretor, Galiza)

Em concreto, os trabalhadores com DI da amostra foram objeto de treinamento pelos chamados Plano Global de Autonomia e Plano de Ócio ${ }^{5}$, que são dotados de recursos que permitem treinar individualmente vários trajetos, usando transportes públicos (ônibus, trem/comboio ou barco), para que, futuramente, possam mobilizar-se autonomamente no espaço público Esse treinamento individual é feito de acordo com as necessidades de cada interveniente, para que cada um per si, torne-se competente para se deslocar autonomamente, sobretudo quando for incluído no mercado de trabalho.

Vamos a ver, custa-lhe por exemplo ir ao trabalho, ele agora vai e vem mas antes teve que haver um treino com os autocarros que tinha que apanhar durante um determinado tempo. Pois tranquilamente nuns quinze ou vinte dias a B. foi-lhe ensinando. Quando há uma viagem nova que tem que fazer, nesses momentos temos que explicar-lhe, ir com ele várias vezes, bom um pouco assim. (familiar, Galiza)

\footnotetext{
${ }^{5}$ Esse programa é desenvolvido apenas por uma das organizações da Região Autônoma da Galiza, consistindo, sinteticamente, em apoiar os trabalhadores com DI para que se reúnam e escolham conjuntamente para onde querem ir e o que querem fazer em termos de atividades de recreação e lazer.
}

|Fed. Nac. das Apaes- Fenapaes | Brasília/DF | v.1 | no 9 | P. 22 - 43 | jan./jun.2018 |ISSN 2237-4329| 
Em termos práticos, o treinamento faz-se, inicialmente, nos deslocamentos, desde os locais de residência até as instalações das organizações de reabilitação e regresso a casa. Posteriormente, estende-se para os trajetos entre as residências e os locais de trabalho. Finalmente, alarga-se em termos geográficos, para que os futuros trabalhadores sejam também autônomos para se deslocarem para os espaços públicos ou privados onde decorrerem atividades culturais, esportivas, de recreação e lazer que desejam se envolver ou praticar, podendo tratar de assuntos do seu interesse, visitar amigos ou familiares, estabelecer e alimentar relações de amizade e amorosas, Em alguns casos, o treinamento inclui idas e vindas a/de locais que não fazem parte das normais rotinas da vida quotidiana, contribuindo, de forma efetiva, para uma melhoria da qualidade de vida na dimensão da Vida Independente.

Ensinamos que venham sozinhas primeiro ao centro, porque é muito importante de onde trabalha ou estuda possa vir sozinho. Quem faz isto são os formadores, é o que faz o "Me Muevo". [...] Já sabes a mecânica: $1^{\circ}$ acompanhamos: $2^{\circ}$ seguimos; $3^{\circ}$ depois que não nos veja, durante o tempo que seja necessário. E não é o mesmo um rapaz que viva aqui ao lado e um que venha de barco, em autocarro e caminhando. (diretor, Galiza)

Ajudámo-la a utilizar o transporte público para que ela se pudesse mover de forma autónoma. Começou por aprender a rota do autocarro que vai desde a sua casa até ao seu trabalho e do trabalho até a casa, o qual levou muito tempo. Inclusive o ato de tocar a campainha para sair na paragem quando era a sua vez. Foi um treino difícil porque sempre passava o local de paragem, mas nos dias de hoje ela movimenta-se e vai ao seu trabalho sozinha e volta para casa sozinha. Vem à Fundação sozinha e volta sozinha para a sua casa. E, vai às atividades de ócio e se ficam em lugares conhecido ela sabe movimentar-se. (formador, Galiza)

Ao se envolverem nesse tipo de práticas e com a resiliência como que as fazem, os agentes das organizações da Região Autônoma da Galiza seguem a regra de que é possível, com treino persistente e apoio pessoal, as pessoas com DI tornarem-se autônomas na mobilidade no espaço público e aplicam os recursos distributivos e de autoridade de que dispõem nessa ação. Ou seja, elas sabem e acreditam que atingir um elevado nível de autonomia no espaço público contribui para melhorar a qualidade de vida, condição fundamental para tornar a vida dos futuros trabalhadores com DI mais independente, aumentando as suas oportunidades de participação em diversas atividades da vida quotidiana.

Com essas práticas, os agentes das organizações da Região Autônoma da Galiza possibilitam que os trabalhadores com DI da amostra (e outros) sejam, na sua larga maioria, bastante autônomos e independentes para irem ao cinema, à praia, ao teatro, visitem museus, fotografarem os lugares que visitam, frequentarem discotecas e passearem por vários locais do espaço público, incluindo lugares 


\section{Apøe Ciênci@ Artigo}

apaeciencia.org.br/revista

pouco ou nada conhecidos: "Todos os dias (uso de transportes públicos)". (trabalhador, Galiza). “Ginásio, natação, trabalho, passear com amigos (uso de transportes públicos)”. (trabalhador, Galiza)

Ao realizarem, como o fazem, um treinamento variado e exaustivo para dotar os futuros trabalhadores de competências para a mobilidade autônoma no espaço público, ainda que de forma por si controlada, os agentes organizacionais agem no sentido do que discursivamente afirmam intencionar fazer, alinhando a consciência discursiva com a consciência prática. Com a sua ação exercem a agência ao serviço da qualidade de vida em termos de fomento de uma vida independente para aquelas pessoas, resultando da sua práxis importantes contributos que questionam o socialmente instituído, i.e., o sistema de regras sobre a deficiência no sentido, não da sua reprodução, mas da sua transformação, na medida em que a sua ação permite contrariar tanto a regra prescritiva, segundo a qual as pessoas com deficiência "devem ser supervisionadas e protegidas", quanto a regra classificativa, de que "não são competentes para se movimentarem autonomamente no espaço público".

\section{CONSIDERAÇÕES FINAIS}

Dos resultados obtidos pela análise das práticas dos agentes das organizações de reabilitação profissional que visam dotar os futuros trabalhadores com DI, podemos retirar duas importantes conclusões, que provam como a ação e a estrutura se influenciam mutuamente, em conformidade com o conceito de dualidade da estrutura. A primeira, respeita o fato de os agentes organizacionais da Região Norte de Portugal, no processo de capacitação dos futuros trabalhadores para serem autodeterminados ou terem uma vida mais independente, exercerem a agência, de tal modo que da sua ação, vista a partir das práticas realizadas para os tornar competentes no usufruto dos tempos livres e em termos de autonomia na mobilidade no espaço público, emerja, sobretudo a reprodução de normas do sistema de regras sociais sobre a deficiência.

Se por um lado, pela sua consciência discursiva, revelam ter intenções positivas, assentes em boas razões práticas e morais, para atenuarem as desvantagens sociais sentidas pelas pessoas com DI, por outro, das suas práticas decorrem consequências não intencionais, que contribuem para reproduzirem regras que mantêm em vigor no sistema social a situação de dependência e marginalização das pessoas com deficiência. Ou seja, podemos inferir que da consciência prática dos agentes da Região Norte de Portugal emerge a prática de se substituírem as organizações das 


\section{Apøe Ciênciø Artigo}

apaeciencia.org.br/revista

comunidades locais, que consideram impreparadas para lidarem com as pessoas com DI e também às famílias, pois consideram que essas não conseguem, ou não querem completar, com eficácia, o processo de socialização primária dos seus membros com deficiência.

A segunda, reporta-se ao fato de, em contrapartida, das práticas dos agentes das organizações da Região Autônoma da Galiza decorrer que tais práticas seguem, com maior intensidade pelo menos, as regras transformadoras que intencionam estabelecer a reprodução das normas do sistema de regras sociais da deficiência. Baseamo-nos nas evidências que mostram que a sua consciência discursiva revela maior consonância com a sua consciência prática, destacando-se o fato de recorrerem preferencialmente aos recursos das comunidades locais e estimularem as famílias a mudarem os seus comportamentos não inclusivos. Destacamos, portanto, que os agentes Galegos evitam, estrategicamente, substituírem-s, tanto às organizações de recreio e lazer das comunidades locais quanto às famílias, preferindo usar os seus recursos distributivos e de autoridade para obterem sua colaboração nas práticas com que intencionam produzir condutas autodeterminadas e tornarem a vida das pessoas com DI mais independente.

Finalizamos, propondo que as pesquisas, nessa temática, sejam feitas tendo em vista a realização de estudos longitudinais de corte, i.e., em que se analise a realidade, usando a mesma amostra de pessoas com DI, nomeadamente em intervalos temporais de, no máximo, 4 a 5 anos, seguindo com regularidade num dado espaço tempo, os efeitos das práticas organizacionais na Qualidade de Vida dessas pessoas. Propomos, também, que a certificação da qualidade das organizações do setor social que se ocupam da reabilitação profissional das pessoas com DI e as ações de qualificação dos profissionais e dirigentes, incorporem módulos de formação que tenham em atenção a necessidade de autoavaliarem as suas práticas, em termos da sua contribuição para a (re)produção do sistema de regras sociais sobre a deficiência.

\section{REFERÊNCIAS}

ALONSO, J. V. García (coord.) El Movimiento de Vida Independiente: Experiencias Internacionales. Madrid: Fundación Luis Vives, 2003.

AMADO, J. S. A técnica de análise de conteúdo. Revista Referência, v. 5, p. 53-63, 2000.

BARDIN, L. Análise de conteúdo. São Paulo: Edições 70, 2011.

BURNS, T.; FLAM, H. Sistema de Regras Sociais. Lisboa: Celta, 2000. 


\section{Apøe Ciênciø Artigo}

apaeciencia.org.br/revista

CENTENO, A.; LOBATO, M.; ROMAÑACH, J. Indicadores de Vida independiente (IVI) para la evaluación de políticas y acciones desarrolladas bajo la filosofía de Vida Independiente. 2008. Disponível em: http://www.minusval2000.com/pdf/Indicadores_de_Vida_Independiente.pdf. Acesso em: 20 dez. 2015

CARR, A. J.; HINGGINSON, I. J. Measuring quality of life: are quality of life measures patient centred? British Medical Journal, v. 322, p. 1357-1360, 2001.

CHARMAZ, K. Constructing grounded theory: a practical guide through qualitative analysis. Londres: Sage Publications, 2006.

CORDEIRO, M.P. Ativismo e deficiência: um estudo sobre os repertórios que dão sentido à vida independente. Psicologia em Revista. Belo Horizonte, v. 15, n. 2, p. 114-131, 2009.

CRESWELL, J. Research Design, Qualitative, Quantitative, and Mixed Methods Approaches. London and New Delhi: Sage Publications, 2003.

CUMMINS, R.A., The domains of life satisfaction: an attempt to order chaos. Social Indicators Research, v. 38, p. 303-328, 1996.

CUMMINS, R. A. (Eds.) Assessing quality of life. In: Brown, R. Quality of Life for People with Disabilities: Models, Research and Practice. Cheltenham: Stanley Thornes, 1997. p. 116 - 150

DUARTE, T. A possibilidade da investigação a 3: reflexões sobre triangulação (metodológica). CIES e Working Papers, v. 60, 2009. Disponível em: https://repositorio.iscteiul.pt/bitstream/10071/1319/3/CIES-WP60\%20_Duarte.pdf. Acesso em: 03 out. 2019.

FERNANDES, L. M.; VEIGA, C. V.; SILVA, C. A. Autodeterminação e Vida Independente. In: VEIGA Carlos Veloso da e Luísa Martins Fernandes (Org.), Inclusão Profissional e Qualidade de Vida, Vila Nova de Famalição: Húmus, 2014. p. 189 - 210

FERNANDES, L. M. Ação Organizacional e Qualidade de Vida. Um estudo comparado do Norte de Portugal e Galiza no campo da Deficiência Mental. 2017. f. Tese (Doutorado), Faculdade, Universidade do Minho, 2017

FIELDING, N.; SCHREIER, M. Introduction: On the Compatibility between Qualitative and Quantitative Research Methods. In Forum Qualitative Sozialforschung/Forum: Qualitative Social Research, v. 2, n. 1, 2001. Disponível em: http://www.qualitativeresearch.net/index.php/fqs/article/view/965/2106. Acesso em: 27 out. 2017.

FLICK, U. Métodos Qualitativos na Investigação Científica. Lisboa: Monitor, 2005.

GIDDENS, A. Central Problems in Social Theory - Action, Structure and Contradiction in Social Analysis. London: Macmillan Press Ltd, 1979.

Fed. Nac. das Apaes- Fenapaes $\mid$ Brasília/DF $\mid$ v.1 | no 9

P. 22 - 43 |jan./jun.2018|ISSN 2237-4329| 


\section{Apøe Ciênciø Artigo}

apaeciencia.org.br/revista

GIDDENS, A. A constituição da Sociedade. São Paulo: Martins Fontes, 2003.

GUERRA, I. Pesquisa Qualitativa e Análise de Conteúdo. Sentidos e formas de uso. Parede: Princípia, 2012.

IÁÑEZ, D. A. Vida Independiente y Diversidad Funcional: Resultados de una investigación social aplicada en la provincia de Sevilla. Portularia, España, v. 9, n. 1, p. 93-103, 2009. Disponível em: https://www.redalyc.org/pdf/1610/161013161009.pdf. Acesso em: 01 out. 2019.

JUNQUILHO, G. Condutas gerenciais e suas raízes: uma proposta de análise à luz da teoria da estruturação, Revista de Administração Contemporânea, v. 7, p.101-120, 2003.

KEITH, K. D. \& SCHALOCK, R. Cross-cultural Perspectives on Quality of Life. American Association on Mental Retardation: Washington, DC, 2000.

LABREGÈRE, A. Les personnes handicapées, Notes et Études Documentaires. La Documentation Française. 1981. p. 4611-4612

LLOBET M. Cuidados y Calidad de Vida en Vilafranca del Penedés: Los mayores de 75 y más años atendidos por el servicio de atención domiciliaria y sus cuidadores familiares, 2009. Dissertação (Doutoramento), Universitat de Barcelona.

MANIFESTO de Tenerife. Promovamos la Vida Independiente - Acabemos con la discriminación hacia las personas con discapacidad. 2003. Disponível em: http://www.independentliving.org/docs6/tenrife20020426sp.html. Acesso em: 20 maio 2015.

MOONS, P., BUDTS, W.; GEEST, S de. Critique on the conceptualisation of quality of life: a review and evaluation of different conceptual approaches. International Journal of Nursing Studies, v. 43, p. 891-901, 2006.

NIRJE, B. The right to self-determination. In W. Wolfensberger (Eds.), Normalization: The principle of normalization. Toronto: National Institute on Mental Retardation, 1972. p. 176-200

STRAUSS, A.; CORBIN, J. Pesquisa Qualitativa - Técnicas e procedimentos para o desenvolvimento de teoria fundamentada. 2. ed. Porto Alegre: Artmed, 2008.

VEIGA, C. As regras e as práticas - Fatores organizacionais e transformações políticas das pessoas com deficiência. Lisboa: Secretariado Nacional para a Reabilitação e Integração das pessoas com deficiência, 2006.

VEIGA, C.; FERNANDES, L.; SARAGOÇA, J.; SILVA, C.; DOMINGUES, I. Teoria e Metodologia. In: Carlos Veloso da Veiga e Luísa Martins Fernandes (Org.), Inclusão Profissional e Qualidade de Vida. Vila Nova de Famalição: Húmus, 2014. p. 9 - 58

VEIGA, C.; FERNANDES, L.; SARAGOÇA, J. Inclusão Profissional, participação comunitária e qualidade de vida. Deficiência Intelectual, v. 10, p. 30-37, 2016.

Fed. Nac. das Apaes- Fenapaes $\mid$ Brasília/DF $\mid$ v.1 | no 9

P. 22 - 43 | jan./jun.2018| ISSN 2237-4329| 


\section{Apae Ciênci@ Artigo}

apaeciencia.org.br/revista

WEHMEYER, M. L. Autodeterminação e Retardo Mental: Montando as peças do puzzle. In: SWITZKY, H. N. (Ed.) Personalidade e Diferenças motivacionais em Pessoas com Deficiência Mental. Mahwah, New Jersey: Lawrence Earlbaum Associates, 2001. p. 147 - 198

WEHMEYER, M. L. Autodeterminación y personas con discapacidad severas. Siglo Cero, Revista Española sobre Discapacidad Intelectual, v. 37, n. 4, p. 5-16, 2006.

WEHMEYER, M. L.; SCHALOCK, R. Self-determination and quality of life: Implications for special education services and supports. Focus on exceptional children, v. 33, n. 8, p. 1-16.

WEHMEYER, M. L.; SCHWARTZ, M. The relationship between self-determination, quality of life, and life satisfaction for adults with mental retardation. Education and Training in Mental Retardation and Developmental Disabilities, v. 33, p: 3-12, 1998. 